\title{
Erzählen in biblischer Literatur: konfessorisch - faktual und fiktional
}

\author{
Hubert Irsigler
}

\section{Zugang: narratologische und hermeneutische Bemerkungen}

Inwiefern und wie wirken faktuales und fiktionales Erzählen in biblischer Literatur zusammen? ${ }^{1}$ Diesen Fragen sucht mein Beitrag anhand einiger exemplarischer Texte vorrangig der alttestamentlichen Bibel nachzugehen. Einleitend umreiße ich die narratologischen und hermeneutischen Voraussetzungen, die mich bei der Untersuchung biblischer Texte im Rahmen der Fragestellung leiten.

\subsection{Zur narratologischen Unterscheidung von, faktual' und, fiktional}

Aus der narratologischen Diskussion greife ich folgende Überlegungen auf: ${ }^{2}$

(1.) Faktualität und Fiktionalität von Erzähltexten beziehen sich auf den jeweiligen Modus des Erzählaktes und damit auf den jeweils textpragmatisch-kommunikativ vorausgesetzten Geltungsanspruch des Erzählten (Klein/ Martínez 2009: 1-4; Martínez/Scheffel 2012: 15, 19-21). Allerdings sind auch textimmanente Merkmale (z. B. der personalen, lokalen und temporalen Deixis) für die Unterscheidung bedeutsam. Faktualität und Fiktionalität des Erzählens wird begründet und entscheidet sich auf der Produktionsebene wie auf der Rezeptionsebene narrativer Texte.

Gérard Genette (1992: 80-89, bes. 83) bringt die Unterscheidung von faktualem und fiktionalem Erzählen bekanntlich auf eine einfache Formel: Bei (text-

1 Biblische Namen werden geschrieben und biblische Bücher werden bezeichnet und abgekürzt nach Fricke et al. (1981). Vgl. entsprechend die Bezeichnungen und Abkürzungen der biblischen Bücher in: Die Bibel. Einheitsübersetzung der Heiligen Schrift. Gesamtausgabe. Psalmen und Neues Testament Ökumenischer Text (2003) 4. Aufl. Stuttgart: Verlag Katholisches Bibelwerk. - In diesem Beitrag verwendete Abkürzungen von biblischen Büchern des Alten Testaments: Gen = das Buch Genesis, Ex = das Buch Exodus, Dtn = das Buch Deuteronomium, Jos $=$ das Buch Josua, $\mathrm{Ri}=$ das Buch der Richter, 1/2 Sam = das erste/zweite Buch Samuel, $1 / 2$ Kön $=$ das erste/zweite Buch Könige, $1 / 2 \mathrm{Chr}=$ das erste/zweite Buch der Chronik, Ijob $=$ das Buch Ijob/Hiob, Koh = das Buch Kohelet/der Prediger Salomo, Jes = das Buch Jesaja, Jer = das Buch Jeremia, Klgl = die Klagelieder, Bar = das Buch Baruch, Am = das Buch Amos, Sach = das Buch Sacharja. - Abkürzungen von Büchern des Neuen Testaments: Mt $=$ Matthäus, $\mathrm{Mk}=$ das Evangelium nach Markus, Lk = das Evangelium nach Lukas, Apg = die Apostelgeschichte.

2 Zumal im mündlichen, als prototypisch verstandenen ,fiktionalisierenden 'Erzählen geht es wesentlich darum, menschliche Erfahrung darzustellen, wie Monika Fludernik hervorgehoben hat (2010: 73), mit Rückverweis u. a. auf Fludernik (1996). Kritisch zur Position, „daß alle Narration fiktional sei“" (Zipfel 2001: 178 f., Anm. 245), vgl. aber auch Fludernik (2001), bes. die Erörterung von „unreliability“ als Indikator von Fiktionalität (2001: 95-101). 
pragmatischer) Identität von Autor und Erzähler liegt eine faktuale Erzählung vor, allerdings nur, wenn der Autor für den Wahrheitsgehalt des Erzählten bürgt. Bei Nicht-Identität hingegen liegt eine fiktionale Erzählung vor, wenn der reale Autor einen Erzähler ,erfindet'. Jedoch ist die Identität von Autor und Erzählerinstanz, wie sie für die faktuale Erzählung charakteristisch ist, keineswegs immer zuverlässig zu ermitteln. ${ }^{3}$ Bei alttestamentlichen Erzähltexten, von denen uns ein riesiger ,garstiger Graben' an Zeit, Geschichte und Lebenswelt trennt, können wir meist nicht den realen Autor erschließen, eher noch Verfasser- und Überliefererkreise. Plausibler lässt sich auf den Autor z. B. bei authentisch erzählten prophetischen Visionsberichten, Memorabilien in Ich-Form, schließen, wie im Visionsund Sendungsbericht des Jesaja in Jes 6,1-11 oder den Visionsberichten des Amos, des Jeremia und des Sacharja in Am *7-9; Jer 1,11-14; Sach *1-8. ${ }^{4}$

(2.) Faktuales Erzäblen ist lebenswirkliches Erzählen oder Erzählen mit dem Geltungsanspruch der Referenz der erzählten Personen, Handlungen und Ereignisse auf außersprachliche Wirklichkeit, d. h. mit dem Geltungsanspruch der zumindest prinzipiellen Referenzialisierbarkeit des Erzählten. Anders gesagt, der Autor bzw. der Erzähler tritt mit dem Anspruch auf, authentisch, d. h. glaubwïrdig zu erzählen, reale Sachverhalte darzustellen (auch wenn er lügen sollte!). Er will seine Adressaten/Rezipienten von der Wahrheit des Dargestellten überzeugen. Mit Klein/Martínez lassen sich neben deskriptiven auch normative und voraussagende Wirklichkeitserzählungen als nicht-literarische Erzählungen unterscheiden, was jedoch auch für ,literarische ${ }^{6}$ Texte zutreffen kann (2009: 6 f.). ${ }^{5}$

(3.) Fiktionales Erzäblen ist allgemein wesentlich gekennzeichnet durch die Konstruiertheit der erzählten Geschichte bzw. der Handlungsfolgen (fictio) und die Erfundenheit der erzählten Ereignisse (fictum). ${ }^{6}$ Auch die fiktive Erzählerinstanz behauptet einen Wirklichkeitsbezug des Erzählten, allerdings eine Referenz auf eine ,nur' narrativ entworfene imaginierte Text-Welt der erzählten Geschichte (Klein/Martínez 2009: 2 f.). Die fiktionale Erzählung kann ihre Fiktionalität durch Fiktionalitätsmerkmale signalisieren, andererseits aber kann sie diese auch durch Mimesis, Nachahmung faktualer wirklichkeitsbezogener Darstellungsformen oder Schauplatzreferenzen verschleiern.

Solche Fiktionalitätssignale wie die Darstellung von Bewusstsein, die Vermittlung von Gedanken und Gefühlen, von Wahrnehmung und Reflexion, nicht re-

3 Sie gilt nur dann, wenn „die ernsthafte Beglaubigung einer Erzählung durch den Autor, der für ihren Wahrheitsgehalt bürgt" (Genette 1992: 85, entsprechend 88), gegeben ist, sprechakttheoretisch gesprochen, wenn die Aufrichtigkeitsbedingung für den faktualen Erzählakt bzw. das Erzählte erfüllt ist.

4 Ein Sternchen (*) bei einer biblischen Textstelle verweist auf die Annahme einer gegenüber dem kanonischen ,Endtext' vorgegebenen älteren bzw. primären Textform.

5 Vgl. zur „Literarizität“ Barsch (2001: 376 f.); zur grundsätzlichen Unabhängigkeit von Fiktion und Literatur Zipfel (2001: 320-22).

6 So Fludernik (2010: 74) in Zusammenfassung von Wolf (1993). Die Erkenntnis dieser Konstruiertheit bzw. Erfundenheit hängt entscheidend vom Wissensstand des Rezipienten ab. 
ferenzialisierbare Gespräche in wörtlicher Rede, ein allwissender Erzähler, unwahrscheinliche und unglaubwürdige Elemente usw. sind nicht völlig eindeutig. Wie das textpragmatisch-kommunikative Verständnis eines Textes kann auch das Verständnis von Fiktionalitätssignalen nach historischen oder sozialen Kontexten variieren. ${ }^{7}$ Das Verstehen eines biblischen Erzähltextes einerseits auf der Ebene der historischen Textproduktion oder Textüberlieferung und -verwendung und andererseits auf der Ebene einer aktuellen Textrezeption kann durchaus unterschiedlich ausfallen: Was auf der Ebene der historischen Textproduktion oder Textüberlieferung im Sinne des faktualen Erzählens gilt, kann auf der Ebene einer aktuellen analytischen Rezeption als fiktionales Erzählen verstanden und beschrieben werden. ${ }^{8}$

Dass die fiktional transportierte Textbotschaft in einem das Historische übersteigenden Sinn nicht weniger wabr ist, hat schon Aristoteles anerkannt (vgl. Poetik: 9. Kap., 1451b). Im fiktionalen Erzählen geht es um eine die Rekonstruktion gewesener Wirklichkeit übersteigende neue Sinnbildung. Mit anderen Worten, fiktionales Erzählen ist Erzählen mit dem Geltungsanspruch einer „Sinnbildung im Medium der Literatur“ (Seip 2002: 195). Erzählt wird mit einer „Offenheit“ $(196)^{9}$ des Textes, die dem Leser Identifikations- und Anschlussmöglichkeiten eröffnet, wie etwa in der biblischen Josefsgeschichte oder im Buch Ijob/Hiob.

7 Martínez/Scheffel (2012: 17): „Fiktional ist ein Text demnach nicht an und für sich, sondern in einem bestimmten historischen und sozialen Kontext, d. h. er ist fiktional für ein Individuum, eine Gruppe, eine Gesellschaft, in einer bestimmten Situation, in einer bestimmten Epoche."

8 Schwierig ist die Frage eines Fiktionalitätsbewusstseins auf der Ebene der Textproduktion in biblischen (Geschichts-)Erzählungen, vgl. Oeming (1984: 261 f.). Fiktionsbewusstsein ist auf der Gestaltungsebene eher anzunehmen, wenn kompositions- und redaktionsgeschichtliche Gestaltungen oder Geschichtskonstruktionen analytisch nachweisbar sind. - Auf der Ebene heutiger Rezeption, nicht ebenso in historischer Textverwendung, erscheint z. B. die Geschichte in Gen 22,*1-19 sicher als fiktional erzählt: die Erzählung von der höchsten Gefährdung des Sohnes Isaak in der extremsten Erprobung der Gottesfurcht Abrahams durch das so anstößige göttliche Geheiß, diesen geliebten Sohn zu opfern. Der Erzähler setzt ,auktorial' ein: Er weiß mehr als die Textfigur Abraham. Er weiß nämlich nach Gen 22,1, dass „der Gott“ Abraham erprobt. Er signalisiert damit zugleich, dass hier keine skandalöse Forderung tatsächlich eingelöst werden soll. Im Anschluss an Genette (1992: 77) können wir von einer externen Fokalisation sprechen: d. h. die Handlungsabfolge, der Plot, wird ganz objektivierend erzählt, ohne jeden Hinweis auf die Gefühle des Abraham. Umso mehr aber wird der Rezipient mit seinen Gefühlen einbezogen und motiviert, Abraham als Paradigma des auch im Nichtverstehen an Gott festhaltenden Gottestreuen für sich zu entdecken.

9 So nach Umberto Eco (2012: 25 ff.). 


\subsection{Grundlegendes zum Verstehen biblischer (Erzäbl-)Literatur}

Biblische Literaturen allgemein und Erzähltexte im Besonderen ${ }^{10}$ verstehen sich auf der Ebene des von einer Glaubensgemeinschaft (Israel/Kirche) getragenen Kanons von Schriften als Texte, die grundlegend religiösen Glauben, Lebens- und Weltdeutung und menschliches Handeln orientieren, und zwar als unterschiedliche menschliche Bezeugungen von Transzendenzerfahrungen. Diese erheben je auf ihre Weise den Anspruch, auf ein wahres Geschehen göttlicher Offenbarung zu verweisen, bei aller geschichtlichen Bedingtheit dieses menschlichen Zeugnisses. Von diesem Offenbarungsgeschehen her erzählen, reflektieren und bezeugen die Texte menschliche Glaubenserfahrungen und mit diesen ein Glaubenswissen, das auf Gotteserkenntnis und deren Weitergabe zielt. Kurz: Biblische Erzählungen haben konfessorischen Charakter.11

Erzähltexte des Alten und Neuen Testaments (im Folgenden AT und NT) zeigen auf der Ebene des Kanons gerade in Schlussabschnitten literarischer Komplexe eine charakteristische, Offenheit ${ }^{c}$ hin auf die Gegenwart von Leserinnen und Lesern biblischer Texte. Dies hat Heinz-Günter Schöttler (2006: 34-64) eindrucksvoll nachgewiesen. Damit ist jene Kompetenz biblischer Texte angesprochen, die Schalom Ben Chorin die "paradigmatische Transparenz“ (1991: 305) biblischer Texte genannt hat, nämlich ihre modellhafte orientierende Durchsichtigkeit hin auf je neue Lebensgeschichten und Erfahrungen von Menschen. Dieser Geltungsanspruch, paradigmatisch transparent zu sein, lässt sich exemplarisch an der Exodus-Überlieferung, der Erzählung vom Auszug der Mose-Gruppe aus Ägypten, d. h. von der Rettung der aus späterer Sicht so genannten „Israeliten“ am „Schilfmeer" bzw. einfach am „Meer“ (Ex 13,17-14,31; 13,21; 15,1-21) veranschaulichen. So heißt es im nachbiblischen Mischna-Traktat Pesachim (X, 5): „In jedem Zeitalter ist jeder verpflichtet, sich vorzustellen, als sei er selbst aus Ägypten gezogen, denn es heißt [Ex 13,8]: An jenem Tag sollst du deinem Sohn also erzählen: Wegen dessen, was der Herr für mich getan hat, als ich aus Ägypten zog." $" 12$

Wenn die Lesenden der Bibel dies aktualisierend jeweils so verstehen sollen, als seien sie selbst betroffen, dann erhält der biblische Text die Funktion eines Modells, eben jene paradigmatische Transparenz hin auf neue Lebensgeschichten von Rezipienten des Textes. Dieser Geltungsanspruch des Modellhaften, dieses Transpa-

10 Eine ausgezeichnete literaturwissenschaftliche Einführung in das Erzählen der Hebräischen Bibel bietet Bar-Efrat (2006). Eine gute Einführung in den „Umgang mit der Fiktionalität biblischer Texte“ bietet Schöttler (2006). Vgl. bes. auch Kutzer (2006). Kaum berücksichtigt bleiben allerdings die Fragen des ,faktualen' Erzählens! Zur Erzählliteratur der Bibel in der englischsprachigen Literatur vgl. exemplarisch Licht (1986), Sternberg (1987), Burridge (1992), Bodine (1995) und die eingehende Darstellung von „narrative art and poetry“ in den Samuelbüchern durch Fokkelman (1981-93).

11 Das gilt sogar noch für eine Schrift wie das Hohelied, bestehend aus erotischen Liebesliedern. Auf der Ebene des Kanons werden diese Lieder eingebunden in das Gottesverständnis Israels, sie werden zu Zeugnissen der Schöpfermacht Gottes, die Liebeskraft schenkt.

12 Übersetzt im Anschluss an Goldschmidt (2002: 665). 
rent-Sein für Erfahrungen und Lebenssituationen der Lesenden kommt dem biblischen Text mit seinem konfessorischen Charakter auf der Ebene des Kanons zu, gleich, ob es sich um einen primär faktual oder fiktional erzählten Text handelt. Das Modellhafte aber, verstanden als Leseanweisung - lies ,als ob' du selbst direkt betroffen seiest! - ist eine fiktionale Größe. Die modellhafte Transparenz des kanonisierten biblischen Textes als Literatur ${ }^{13}$ macht aus einem ursprünglich geschichtlich-situationsgebundenen Text einen überzeitlich gültigen und auslegungsoffenen Text, ohne dass dieser das Signum seiner geschichtlichen Verankerung völlig abstreifen müsste. Insofern ist mit der Kanonisierung eine Fiktionalisierung des Textes verbunden. Sie lockert den biblischen Einzeltext aus seiner ursprünglichen, situativ-kommunikativen Verankerung. Dieses Verständnis der ,Offenheit ${ }^{6}$ des biblischen Textes hängt mit der Bedeutung des Gedächtnisses in Israel zusammen. ,Gedächtnis' (zikkaron) ist nicht bloße Erinnerung an Vergangenes, sondern identitäts- und existenzbegründende Erinnerung, wirksame Vergegenwärtigung des Vergangenen. In solcher Erinnerung soll der Lesende des Glaubens Israels inne werden. „Glaube und Gedächtnis gehören in Israel zusammen“ (Bovon 1989: 36). Dies gilt für die Bibel des Judentums, faktisch die Bibel Jesu bzw. christlich gesprochen für das Alte Testament. Es gilt jedoch auch für das Neue Testament.

Die beschriebene Art der Fiktionalisierung des kanonisierten biblischen Textes, sein Anspruch, modellhaft bzw. paradigmatisch transparent zu sein auf neue Lebenswirklichkeiten von Menschen hin und der Lebensdeutung und Handlungsorientierung zu dienen, wirkt sich auf die Referenzfunktion und den Erzählmodus des Textes aus: Dem biblischen Text kommt eine neue implizite Referenzfunktion zu, nämlich ein paradigmatischer Bezug des Erzählten auf die Kommunikationssituation und Lebenswirklichkeit je neuer Textrezipienten. Insofern ein biblischer Erzähltext auf Wirkung, auf Aneignung und Umsetzung im Leben der Rezipienten zielt, kann man daher m. E. genauer von der sekundären impliziten Dimension einer normativ-faktualen Erzäblung bzw. einer "normativen Wirklichkeitserzäblung" reden (so nach der Terminologie von Klein/Martínez 2009: 6). Diese Dimension wird gerade durch die fiktionalisierende Modellhaftigkeit des Textes ermöglicht und vermittelt.

Diese Zusammenhänge ließen sich biblisch an einem Textbereich besonders gut verdeutlichen, den wir nicht primär zur erzählenden Literatur rechnen: an den Prophetenschriften der Bibel. Ich möchte keineswegs sagen, dass die ursprüngliche, aus der konkreten Redesituation des einzelnen (mündlichen) Prophetenwortes sich ergebende Referenzfunktion durch Verschriftung, Fortschreibung und Bearbeitung bis hin zum vorliegenden Prophetenbuch aufgehoben ist, so Kutzer (2006: 196); aber der Weg bis hin zur Prophetenbuchbildung fiktionalisiert den prophetischen Text, befreit ihn von der ausschließlichen Bindung an die primäre Redesituation, macht ihn neu und umfassender anwendbar, aktualisierbar und wirksam. ${ }^{14}$

13 Liss (2004: 32): „Kanonbildung ist damit Literaturbildung im eigentlichen Sinn.“

14 Wie von der ,Endgestalt‘ eines prophetischen Textes im Prophetenbuch überlieferungskritisch nach der originären Gestalt von Prophetenworten zurückgefragt werden kann und wel- 
Als Einstieg in meinen Überblick zur Frage nach dem faktualen und fiktionalen Erzählmodus in biblischen Texten wähle ich einen Textzusammenhang aus dem Neuen Testament, das Lukasevangelium. Es wird durch einen erzähltheoretisch besonders interessanten Prolog eingeführt.

\section{Erzäblen im Lukasevangelium}

Der stilistisch gefeilte Prolog des Lukasevangeliums $L k$ 1,1-4 ist einzigartig innerhalb der Evangelienliteratur. Es handelt sich um einen metanarrativen Kommentar einer Erzählinstanz, die nur hier in der Ich-Form auftritt (in V. 3). Ab Lk 1,5 wird in der Evangeliumserzählung mit impliziter Erzählinstanz auktorial erzählt.

1 Da ja schon viele sich daran gemacht haben, eine Erzählung abzufassen über die Ereignisse, die unter uns erfüllt worden sind,

2 so wie (sie) uns die überliefert haben, die von Anfang an Augenzeugen und Diener des Wortes geworden sind,

3 schien es auch mir als dem, der allem von Anbeginn sorgfältig nachgegangen ist, (es) für dich der Reihe nach aufschreiben zu sollen, verehrter Theophilus,

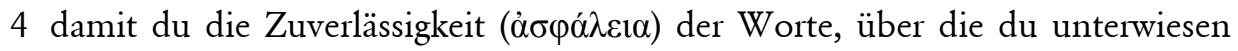
worden bist, genau erkennst.

Der Prolog Lk 1,1-4, stilisiert wie Prologe anderer literarischer Werke der Antike (Bovon 1989: 30 f., 32 f.), leitet wohl nicht nur das Evangelium selbst ein, sondern auch die Apostelgeschichte, die ihrerseits mit einem kurzen Vorwort einsetzt (Apg 1,1-3). Der im Ich-Stil Redende präsentiert sich, allerdings ohne Namensnennung, als Autor des gesamten ,lukanischen' Doppelwerkes, das aus Lukasevangelium und Apostelgeschichte besteht. ${ }^{15}$ Nun ist methodisch-narratologisch gewiss zwischen dem expliziten Ich des Prologs, der impliziten Erzählerinstanz in der gesamten Evangeliumserzählung und dem realen Autor zu unterscheiden. Ich sehe aber keinen Grund, die Ich-Rede des Prologs nicht sachlich auf den realen Autor dieser Evangeliumserzählung zu beziehen. Es geht um das, was Genette für eine sachliche Identität von Autor und Erzähler voraussetzt, nämlich um „die ernsthafte Beglaubigung einer Erzählung durch den Autor, der für ihren Wahrheitsgehalt bürgt“ (1992: 85). ${ }^{16}$ Der Prolog dient dem Nachweis der Glaubwürdigkeit, der Au-

cher Wandel von textpragmatischen Mitteilungs- und Wirkfunktionen damit verbunden ist, habe ich am Beispiel von Hosea Kap. 11 zu zeigen versucht, vgl. Irsigler (2007: 87-121).

15 Der Name des Verfassers fällt im Prolog auffälliger Weise nicht. Nach der altkirchlichen Tradition wird dieses Evangelium dem zeitweiligen Paulusmitarbeiter Lukas zugeschrieben. Das kurze Vorwort der Apostelgeschichte in Apg 1,1-3 verweist ausdrücklich auf das Lukasevangelium als „das erste Buch“ des Werkes des Verfassers und entsprechend auf den Prolog Lk 1,1-4 zurück, wiederum mit „Theophilus“ als Adressaten (Apg 1,1).

16 Schmitz insistiert im Blick auf Lk 1,1-4 auf der Aussage: „Die Instanz, die einen Text erzählt, ist nicht mit dem realen Autor identisch“ (2006: 143). Gewiss ist dieses Ich „die Erzählinstanz, die die folgende Geschichte über das Leben von Jesus aus Nazareth erzählt“ (143). Der gebildete Autor stellt sich im Prolog als ein Literat und Historiograph vor, um 
thentifizierung des Erzählers und des Erzählten. Der angesprochene Leser „Theophilus", wohl ein sog. Heidenchrist, soll verlässliche Informationen über Ereignisse, über Leben, Tod und Auferstehung des Messias erhalten. Der Autor will über seine diskret kritisierten Vorgänger ${ }^{17}$ hinaus zuverlässig, präzise und umfassend berichten. Er will mit den erzählten historischen Ereignissen zugleich den Inhalt seines Glaubens vermitteln, den sich der Adressat (mit Theophilus sind alle weiteren Lesenden und Hörenden angesprochen) zu eigen machen kann. Dieser, Lukas des Prologs will also überzeugen, bestätigen, die Wahrheit der Ereignisse bekräftigen. Diese Art der Rezeptionsbezogenheit bestätigt den faktualen Charakter der Evangeliumserzählung. Im Erzählen verbinden sich unlöslich der dokumentarische Anspruch und die theologische Intention. Die lukanische Evangeliumserzählung versteht sich ihrem Geltungsanspruch gemäß somit wesentlich als konfessorische und faktuale Erzäblung. Sie ist allerdings in einem doppelten Sinne faktual, nämlich einerseits deskriptiv mit dokumentarischem Anspruch als Darstellung realer, wahrer Sachverhalte und andererseits zugleich und vor allem auch normativ, da die Evangelienverkündigung auf Aneignung durch ihre Adressaten zielt. ${ }^{18}$

Das schließt nicht aus, dass die Evangeliumserzählung fiktionale Züge, Erzäblverfabren und Inhalte impliziert, etwa schon hinsichtlich des konstruierten Aufbaus, der nur chronologisch gedachten Anordnung des Erzählstoffes ${ }^{19}$, auch hinsichtlich der spezifisch lukanischen Gesamtdeutung des historischen Jesus als barmherzigem Heilbringer der Verlorenen, der Armen, der sozial Entrechteten, der Frauen, der Zöllner und der Sünder. Fiktional sind natürlich die gerade für Lukas so typischen Gleichniserzäblungen; in diesen fungiert Jesus im Evangelium als erzählter Erzähler. Fiktionales bzw. fiktive Elemente zeigen sich dazu im Einzelnen besonders in der lukanischen Kindheitsgeschichte Jesu. ${ }^{20}$ Die Grenze zwischen faktualem und fik-

die Wahrheit und Glaubwürdigkeit seiner Darstellung zu unterstreichen. Er ist selbst kein „Augenzeuge“ (Lk 1,2) mehr, betont aber die Sorgfalt, mit der er den Überlieferungen von Jesus nachgegangen ist. Es besteht kein begründeter Anlass, an der erfüllten Aufrichtigkeitsbedingung der Sprechakte in Lk 1,1-4 bzw. an der Ernsthaftigkeit der Beglaubigung der Evangeliumserzählung durch den realen Autor zu zweifeln, auch wenn dieser wenig von sich selbst und auch seinen Namen nicht mitteilt. Zur Frage nach dem Verfasser des nach der altkirchlichen Tradition dem Lukas zugeschriebenen Evangeliums sowie der Apostelgeschichte vgl. Bovon (1989: 22-24) und Pesch (1986: 25-27).

17 Vor allem das Markus-Evangelium und die Logienquelle Q, d. h. eine Sammlung von Jesus-Worten aus urkirchlicher Tradition, die als eine der Quellen des Matthäus- und des Lukasevangeliums den Verfassern dieser Evangelien vorgelegen haben muss.

18 Zum Lukasevangelium als Beispiel einer „Wirklichkeitserzählung“ vgl. auch Mauz: „Historisch'vom Heiland der Armen und Sünder erzählen“ (2009: 207-10).

19 Dreiteiliger Aufbau mit zwei großen Sondergut-Einschaltungen gegenüber Markus, davor die Kindheitsgeschichte Jesu.

20 Dies kann man z. B. an der Geschichte der Hirten in der Geburtsgeschichte beobachten, die einerseits Jesus mit dem Hirten und König David assoziieren, andererseits signalisieren, dass Jesu Botschaft vom sich ereignenden Reich Gottes gerade für die Armen Heil und Rettung bedeutet - ein charakteristisches Anliegen des ganzen Lukasevangeliums. Hinzuweisen ist auch auf das Paradox, dass das Kind in der Futterkrippe, das keine Herberge findet, der wahre

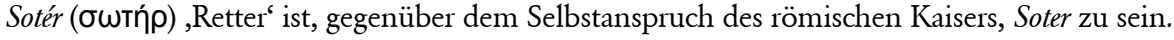


tionalem Erzählen kann fast unmerklich überschritten werden. Gleichwohl bleibt der dominante faktuale Geltungsanspruch des authentisch zuverlässigen Erzählens erhalten. Was Knut Backhaus für die Apostelgeschichte vor dem Hintergrund der rhetorisch-mimetisch-paideutischen Funktionseinheit der hellenistisch-frühreichsrömischen Geschichtsschreibung feststellt, gilt entsprechend für das Evangelium des Lukas: „Seine fiktionalen Erzählelemente wollen die historischen Ereignisse beleuchten, kompakt und transparent werden lassen, vertiefen, nicht ersetzen“ (2007: 41). Entscheidend ist für den Evangelisten die auch mit fiktionalen Zügen erzählte Botschaft, eine authentische Deutung Jesu als des Messias/Christus, des wahren Sohnes Gottes, der die Menschenliebe Gottes, seine unbedingte barmherzige Zuwendung offenbart, verkündet und verkörpert. Es handelt sich also um das, was man mit Recht „narrative Theologie“ genannt hat. ${ }^{21}$

\section{Fiktionale Erzäbltexte im Alten/Ersten Testament}

\subsection{Dominant fiktionale Texte im Überblick}

Einige Schriften bzw. Bücher des AT machen aus ihrem fiktionalen Charakter keinen Hehl, sondern stellen ihre Fiktionalität mehr oder weniger plakativ zur Schau. Aus der Hebräischen Bibel sind zu nennen: die Königsfiktion im Buch Kohelet in Kob 1,12-2,11/26; die Bücher Ijob/Hiob und Ester (erweitert in griechischer Fassung) sowie das prophetische parabelhafte Jona-Büchlein. Als fiktional zu nennen ist auch das apokalyptische Buch Daniel (hebräisch und aramäisch, Zusätze in der griechischen Fassung) mit literarischen Visionsschilderungen, die politisch motiviert sind.

Von den griechisch überlieferten sog. deuterokanonischen Büchern verschleiern ihre Fiktionalität keineswegs die Bücher Tobit, Judit, Baruch (15, mit Bar 6: Brief des Jeremia); weitgehend fiktional erzählend ist auch das 2. Makkabäerbuch mit ehrlichem Vorwort (2,19-32), in dem der Erzähler bekennt, dass er nicht Geschichtsschreiber sein will, sondern Nacherzähler, der unterhaltend und der religiösen Erbauung nützlich schreibt, auch wenn er sich einer auszugshaften Rezeption des Geschichtswerks des Jason von Zyrene $(2,23)$ bedient.

Ich greife ein Textbeispiel aus der Weisheitsliteratur des biblischen Israel heraus:

\subsection{Das Buch Ijob (Hiob)}

Das hebräische Buch Ijob spiegelt geradezu in seiner hochpoetischen Gestaltung mit Rahmenerzählung und zentraler Dialog-Dichtung und in seiner ebenso gelehrten wie bilderreichen Sprache die Schwere der in ihm durchkämpften mensch-

21 Mit Weinrich (1973) und z. B. auch Metz (1973), Wenzel (1996, 1997); vgl. auch Wenzel (2008: 75-106) zu einer theologischen Hermeneutik der Narration. 
lichen Anfechtung wider. Grund der Anfechtung ist in der zentralen Dichtung (ab Kap. 3) das als ungerecht und unerklärlich empfundene Leiden, das zu einer für die Ijob-Figur unerträglichen menschlich-göttlichen Beziehungsproblematik führt. ${ }^{22}$ Das komplex erzählende Ijobbuch ist poetische Literatur, die sich sowobl durch die Konstruiertheit der Gestaltung (fictio) wie durch das Erfundensein der IjobGeschichte (fictum) auszeichnet. Das Ijobbuch ist fiktional erzäblende Literatur, die gerade deshalb so beispielhafte allgemein-menschliche Gültigkeit beansprucht.

Syncbron gesehen erscheint das Ijobbuch wie ein kleines Gebirge an Literatur mit mehreren Höhenzügen. Dass das Ijob-Buch diachron gesehen aus einer über Jahrhunderte sich erstreckenden Entstehungsgeschichte hervorgegangen ist, hat die exegetische Forschung schon seit dem 19. Jh. konsensfähig erwiesen. Im Werdegang des Ijobbuches zeigt sich der immer neue Versuch, mit den IjobGrundfragen zurechtzukommen und Antworten zu finden, die dann in die Gesamtkonstruktion des Buches eingegangen sind.

Die Rabmenerzäblung, eine einstmals selbstständige weisheitliche Lehrerzählung liegt in Ijob 1-2,10 und 42,10*-17 vor; sie ist schon erweitert durch die beiden Himmelsszenen mit den Gesprächen zwischen JHWH und „dem Satan“, der stets mit Artikel eingeführt wird als Bezeichnung der Widersacherfunktion (kein genuiner Eigenname). Der Rahmenerzählung geht es um die Frage: Wie verhält sich der rechtschaffene gottesfürchtige Mensch richtig, wenn ihn unerklärliches Leid trifft? Die Erzählung setzt geradezu märchenhaft ein: „Es war ein Mann im Lande Uz, dessen Name Ijob war" $(1,1)$. Wo das Land Uz liegt (im nördlichen Ostjordanland oder doch eher weit im Süden Palästinas in von Edom beherrschtem Gebiet) ${ }^{23}$ wird nicht gesagt. Eine Zeitbestimmung fehlt ganz. Schon der Einsatz der Erzählung deutet darauf hin, dass es nicht um eine bestimmte geschichtliche Gestalt geht. Ijob ist von vornherein Beispiel eines Menschen, den unerklärliches Leid trifft; er repräsentiert ein modellhaftes Menschenleben und -geschick, in dem sich Menschen, unabhängig von Raum und Zeit, je auf ihre leidvolle Weise wiederfinden können. Mir scheint es nicht ausgeschlossen, dass auch der Name Ijob mit Bedacht gewählt ist. Der Name Ijob leitet sich nämlich von einer Fragepartikel und dem theophor, d. h. als Gottesbezeichnung verstandenen Substantiv 'ab, Vater' her, wie akkadische Namensparallelen zeigen. ${ }^{24}$ Er bedeutet als Fragesatzname „Wo ist der (göttliche) Vater?“. Damit ist eine Grundperspektive des Ijobbuches angesprochen, die schon implizit in der Rahmenerzählung präsent ist, dann aber in der zentralen Dichtung von der IjobFigur in ihrem Rechtsstreit mit Gott explizit formuliert wird: Der Mensch fragt

22 Im Bereich der sumerisch-akkadischen (und altägyptischen) Auseinandersetzungsliteratur kommen dem Ijobbuch in dieser Hinsicht am ehesten noch die babylonischen Dichtungen Ludlul bel nemeqi (Ich will preisen den Herrn der Weisheit) und die akrostichische sog. babylonische Theodizee nahe.

23 Wahrscheinlich primär im nördlichen Hiğāz im nördlichen Westarabien, vgl. zur Diskussion $H A H$ (2013: 938). Das Land Uz ist neben Ijob 1,1 noch in Klgl 4,21; Jer 25,20 belegt.

24 Vgl. HAH (2013: 45): aus: ,aya 'abu; Fohrer (1989: 71 f.). 
nach dem Grund des Handelns Gottes, anders gewendet, nach dem dem Menschen gütig (als ,Vater') zugewandten Gott.

Ein Fiktionalitätssignal in der Rahmenerzählung ist zweifellos auch die Zahlensymbolik, die auf Ganzheit zielt. Vierfach wird Ijob als rechtschaffen bezeichnet: Er ist „recht und redlich und gottesfürchtig und das Böse meidend“ (Ijob 1,1). Sein ursprünglich vollendetes Glück besteht darin, dass er sieben Söhne und drei Töchter hat und dazu reichen Besitz: 7000 Stück Kleinvieh, 3000 Kamele, 500 Gespanne Rinder, 500 Eselinnen und natürlich zahlreiches Gesinde. Wie die alte Lehrerzählung anfängt, so schließt sie auch (42,10*; 42,11-17): märchenhaft! Ijob wird wieder mit zahlreichem, sogar verdoppeltem Besitz gesegnet und hat wieder sieben Söhne und drei wunderschöne Töchter. Er lebt nach all den schrecklichen Ereignissen, die ihn nach den berühmten Ijobsbotschaften $(1,13-$ 19) und in der aussatzartigen Krankheit (2,1-10) getroffen hatten, noch 140 Jahre und stirbt wie ein Patriarch „alt und lebenssatt“ (42,16-17).

In diesen älteren, erzählenden Rahmen eingespannt ist nun die komplexe zentrale Ijobdichtung als erzäblte Reden. Statt des Ijobs der geduldigen ergebenen Daseinshinnahme der Rahmenerzählung führt sie den rebellischen, gegen sein als so ungerecht empfundenes Schicksal aufbegehrenden, mit seinen sog. Freunden und vor allem mit Gott streitenden Ijob ein, der gleichwohl nie von Gott lässt. Die Konstruiertheit der zentralen Dichtung zeigt sich im Aufbau. Die primäre Grundform dieser Dichtung erzählter Reden enthält drei Redegänge des Dialogs Ijobs mit den drei Freunden. Jeder Redegang enthält sechs Reden, drei Reden Ijobs und jeweils darauf eine Freundesrede. ${ }^{25}$ Die Freunde stellen sich als leidige Tröster und als Vertreter einer starren Vergeltungslehre heraus, d. h. eines berechenbaren Tun-Ergehen-Zusammenhangs. Sie gehen nicht nur von der oft gemachten Erfahrung aus, dass ein bestimmtes Tun und Sich-Verhalten eines Menschen ein dem Tun entsprechendes Ergehen hervorruft, sondern wollen umgekehrt aus dem Ergehen auf ein bestimmtes Tun des Menschen schließen, d.h. aus dem leidvollen Zustand Ijobs auf dessen Sünde und Schuld. In der Vorstellung der Freunde Ijobs handelt Gott am Menschen genau nach diesem TunErgehen-Modell; sie vertreten damit ein ideologisiertes Gottesbild. Sie stempeln Ijob zunehmend zum Frevler (Kap. 3-27).

Die Reden schöpfen aus weisheitlicher, psalmistischer und juridischer Tradition. Sie gestalten so die extremste Auseinandersetzung Ijobs mit Gott, genauer mit dem überkommenen weisheitlich geprägten Gottesbild der gerechten Vergeltung. Durchweg sind zwei funktionale Dimensionen der Ijob-Figur lebendig. Einerseits geht es bei Ijob um ein existenziell-persönliches Lebensgeschick, das gleichwohl paradigmatischen Charakter hat. Andererseits geht es ausdrücklich um das allgemein-menscbliche Geschick von schwerem Leid, Hinfälligkeit und Vergänglich-

25 Die allerletzte Freundesrede fehlt. In Ijob 32-37 folgen indes sekundär eingesetzte eigenständige ,Reden Elihus'. 
keit, wie z. B. in den großen Menschheitsklagen Ijobs in Kap. 7 und 14, zugespitzt schon in der auslösenden Klage Kap. 3 (V. 20): Warum gibt Gott überhaupt dem elenden, dem durch Leid verbitterten Menschen Lebenslicht?

Die Gestalt Ijobs wie auch das textimmanent entworfene Gottesbild der IjobFigur, beide werden in der sich verschärfenden Rechtsauseinandersetzung Ijobs mit Gott als literarisch mythisiert mit Hilfe des Chaoskampfmotivs dargestellt. Im Mythos bändigt der Gott das urzeitliche Meeresmonster, um entweder Schöpfung als Ordnung zu ermöglichen oder die geschaffene Welt zu stabilisieren. ${ }^{26}$ Für den leidenden Ijob erscheint Gott als eine solche feindselige, chaotische Macht (z. B. Ijob 16,9-14; 19,6-12). Umgekehrt beklagt Ijob, dass er sich wie das chaotische Urzeitmonster behandelt sieht $(7,12)$; wenn Ijob seinen Geburtstag und seine Empfängnisnacht verwünscht (3,1-10), so wünscht er nichts weniger herbei als den Rückfall der Schöpfungsordnung in das Dunkel des Chaos. Solcherart Mythisierung der Ijob-Figur und ihres Gottesbildes unterstreicht die prinzipielle, überzeitliche und universale Bedeutung der Auseinandersetzung Ijobs mit Gott. Diese Mythisierung aber ist ein nicht zu übersehendes Fiktionalitätssignal in den erzäblten Ijob-Reden.

Worum es in der gesamten zentralen Ijobdichtung bis hin zu den abschließenden Gottesreden und der Ijob-Antwort $(38,1-42,6)$ geht, wird im Redeprozess zunehmend deutlich. Mitteilungsziel ist ein anderes, neu gewonnenes Gottesverständnis. Es taucht schon in den Hoffnungsaufschwüngen Ijobs aus tiefster Verzweiflung auf: Gott als Bürge für den Menschen, als sein „Löser“, der verlorene Integrität wieder herstellt (16,18-22; 19,23-27). Die Gottesreden (38,1-39,30; 40,641,26) mit ihren eindrücklichen Schöpfungsbildern bringen etwas wie eine poetische schöpfungstheologische Rechtfertigung Gottes. Es ist ein Gott, der alles menschliche Begreifen übersteigt, dessen undurchschaubarem, sinnstiftendem, kreativen Handeln der Ijob-Mensch, der in sein menschengemäßes Maß gestellt wird, jedoch trauen darf: „Vom Hörensagen nur hatte ich von dir vernommen“ sagt endlich Ijob, „nun aber hat mein Auge dich geschaut“ $(42,5)$. Es ist ein Schauen als Begegnung, die Vertrauen und Sich-Anvertrauen schafft. Und zugleich eine Leerstelle, die der Leser je auf seine Weise füllen kann und soll.

Denn das Wirkungsziel der ganzen Dichtung ist entscheidend: Der ganze erzählte Redeprozess des Ijobbuches wirkt wie ein therapeutischer Weg, auf den der Leser als ein Ijob-Mensch sich einlassen kann und soll: eine implizit normativfaktuale Dimension der Darstellung. „Die Heilung, die die Figur des Ijob im fiktionalen Text erfährt, gibt der Text weiter an seine Leser“"(Kutzer 2006: 234).

26 Vgl. bes. Fuchs (1993). Sie untersucht eingehend die Verwendung des Chaoskampfmotivs in der Ijobdichtung. 


\section{Fiktionales und konfessorisch-faktuales Erzäblen in den Schöpfungserzäblungen von Genesis 1-3 im Rabmen der biblischen Urgeschichte (Gen 1-9/11)}

Innerhalb der Kapitel des Buches Genesis, die wir als biblische Urgeschichte mit ihren universalen Perspektiven bezeichnen können (Gen 1-9, erweitert bis Gen 11), lässt sich eine Tendenz beobachten, funktional Mythisches, als Urgeschehen jenseits geschichtlicher Zeit, gefiltert durch den Eingottglauben Israels, in eine Geschichtsvorstellung, eben eine Urgeschichte einzubeziehen. Und diese läuft konsequent auf die mit Abraham (in Gen 12) einsetzende Geschichte bzw. Vorgeschichte Israels zu. Es ist klar, dass sich die Ereignisse des Anfangs, der Entstehung von Mensch und Welt jeder einfachen Beschreibung entziehen, sie können aber erzäblerisch fiktional vorstellbar und anschaubar gemacht werden. ${ }^{27}$

Bekanntlich sind in Gen 1-3 zwei sehr unterschiedliche Schöpfungserzählungen, Gen 1,1-2,4a und Gen 2,4b-3,24, redaktionell kombiniert, als die Schöpfungsgrundlage, aber auch als Verstehensvoraussetzung für alles Folgende. Die ältere liegt in der Garten-Eden-Erzäblung Gen *2,5-3,24 vor und geht auf zwei mythisch-narrative Erzählzusammenhänge zurück, einerseits von „dem Menschen" ( $\left.h a={ }^{\prime} a d a m\right)$, der von Gott aus der Ackererde ( $\left.h a={ }^{\prime} a d a m \bar{a}\right)$ erschaffen ist (Herkunftsangabe zielt auf Wesensbeschreibung!), und andererseits von der Erschaffung der Frau als echtem gleichwertigen Gegenüber zum Mann. Gen 2-3 verdeutlicht eine grundlegende anthropologische Ambivalenz. Gen 2 stellt den Menschen in seinen fundamentalen und bleibend gültigen Beziehungen vor: die Grundbeziehung zu Gott als seinem Schöpfer, zum Lebens- und Arbeitsraum, zu den Tieren als Mitgeschöpfen und endlich die ebenbürtige Beziehung von Mann und Frau, ihr Aufeinanderzustreben und ihre Gemeinschaft. Der Mensch, hier eher als Naturwesen mit von Gott geschenkten Entfaltungsmöglichkeiten vorgestellt, lebt da im nichtautonomen Zustand und in ungebrochener Gottesnähe. Anders in Gen 3: In den Tatfolgebestimmungen $(3,14-19)$ der Gebotsübertretung wird die erfahrene tatsächliche Lebenswelt des Menschen, der primären Textrezipienten, vorgestellt: Die Frau gebiert Kinder unter Schmerzen; aus dem ebenbürtigen Verhältnis zum Mann ist faktisch ein Unterordnungsverhältnis geworden. ${ }^{28}$ Der Mann muss sich den Lebensunterhalt im Schweiße seines Angesichts mühevoll verdienen. Den Menschen erwartet der Tod als Rückkehr zu der Erde, von der er genommen wurde. Der Mensch hat sich zwar tragisch aus dem nichtautonomen Zustand in einen Zustand relativer Autonomie ,befreit', aber es ist ein Zustand nur noch gebrochener Gottesnähe. Aus der Sicht der erfahrenen tatsächlichen Lebenswelt des Menschen in Gen 3 erscheint aber der Mensch in Gen 2 und sei-

27 Vgl. auch Kutzer (2006: 206) und insgesamt (206-16).

28 Es wird nach dem biblischen Hohenlied in der Liebe von Mann und Frau wieder aufgehoben: Liebe als Rückkehr ins Paradies! 
ne ungebrochene Nähe zum fürsorglichen Schöpfergott als bleibende potenzielle Schöpfungswirklichkeit gegenüber der tatsächlich erfahrbaren Schöpfung.

Auf eine ähnliche Ambivalenz wie jene zwischen Gen 2 und Gen 3 stoßen wir in der sog. Priesterschrift im Pentateuch aus dem späten 6. Jh. v. Chr. Und wieder geht es um die Kontinuität des Geschaffenen und zugleich um einen Bruch, der sich in der aktuell wahrnehmbaren Wirklichkeit zeigt. Das Eingangsportal der Bibel ist der sehr reflektiert durchkonstruierte Welt- und MenschenSchöpfungsbericht in Gen 1,1-2,4a mit seinem Sieben-Tage-Schema. Der Text verteilt acht Schöpfungswerke des einen königlich souveränen Gottes auf sechs Schöpfungs-Tage. Schon in der planmäßigen, von vornherein literarischen Gestalt mit ihrem Wort- und Tatbericht, mit ihren listenwissenschaftlichen Aufzählungen und ihrer hymnisch konnotierten Redefunktion entfernt sich der priesterschriftliche sog. Schöpfungsbericht deutlich stärker als Gen 2-3 von dem Typ der „ursprünglichen Mythen“ als primär mündlichen traditionellen Erzählungen von den jenseits geschichtlicher Zeit liegenden stiftenden Ursprüngen gegenwärtiger Wirklichkeit. Der Schöpfungsbericht, kurz Gen 1, ist in der Priesterschrift auch gar nicht eigentlich ein Jenseits zur geschichtlichen Zeit, vielmehr der erste Akt der Weltgeschichte, die auf die Geschichte Israels zuläuft. Ziel des Textes in der Werkreihe ist der Mensch, als Mann und Frau, geschaffen als (!) das einzige wahre Bild Gottes auf der Erde. Diese Gottbildlichkeit, aus altorientalischer Königstradition stammend, wird aber nicht ontologisch begründet, sondern funktional erläutert durch eine Kompetenzbeschreibung: Der Mensch ist bestimmt zu kreativ ordnender Herrschaft über die Erde, eine ordnende Leitung der Tierwelt ohne jede Tötung von Tieren; Pflanzen sind die Nahrung für alle lebenden Wesen. Erst recht gibt es keine Herrschaft von Menschen über Menschen! Ziel in der Reihe der Tage ist klar der siebte Tag als Tag der Ruhe und Feier. Es ist der in den ganzen Kosmos eingeschriebene universal gültige Sabbat der Schöpfung.

Von der faktisch erfahrenen Weltwirklichkeit her erscheint das Bild der Schöpfung von Gen 1,1-2,4a als die ideale Weltordnung des Ursprungs. Wie die Welt sich tatsächlich für die Textrezipienten darstellt, das führt die sog. Priesterschrift als literarische Schicht innerhalb des Buches Genesis in ihrem weiteren Verlauf in Gen 9,1-17 aus. Hier geht es um die Zeit nach der Sintflut, die durch die sich ausbreitende Gewalttat der Menschen heraufbeschworen wurde. Wieder gibt es Kontinuität und Diskontinuität. Erhalten bleibt die Würde der Gottbildlichkeit des Menschen in Mann und Frau. Aber das Nahrungsangebot wird jetzt erweitert, weil das Verhältnis Mensch - Tier sich negativ gewandelt hat. Tiere können nun zur Nahrung für Menschen getötet werden. Man kann fragen: Ist dies eine Form der Kanalisierung menschlicher Aggressivität? Wie dem auch sei, Gott gewährt nicht nur den Menschen, sondern allen Lebewesen nach der Sintflut in der Priesterschrift einen Bund als feste Verheißung der Bewahrung und des Bestehens, bildlich veranschaulicht im Zeichen des Regenbogens. 
Was ergibt sich nun für die Frage nach Erzäblmodus und Intention? Wenn wir uns die Garten-Eden-Erzählung von Gen 2-3 vergegenwärtigen, so ist klar, dass hier jede konkrete lokalgeschichtliche Einordnung unmöglich ist. ${ }^{29}$ Das Mitteilungsziel der Erzählung liegt in Gen 2-3 und auch im Wort- und Tat-Bericht von Gen 1 nicht in der Ereignis- und Handlungsabfolge als solcher, nicht im Plot der Erzählung, also nicht im ,Wie ${ }^{6}$ des schöpferischen Handelns Gottes. Diese ,Ereignisse', das ,Wie ' des Uranfangs kann nur fiktional erzählt und so vorstellbar gemacht werden. Zu diesem Zweck wird zeitgenössisches mytho-empirisches Wissen eingesetzt und in Gen 1 allerdings auch sehr deutlich eine entmythisierende Tendenz der Darstellung. Das strukturale Ziel, die entscheidende Textintention liegt, kurz gesagt, im, Dass' des Erzäblten, in der Tatsache, dass der Mensch nach Gen 2 in von Gott geschaffenen tragenden Beziehungen lebt, dass nach Gen 3 die defizitären Erfahrungen des Menschenlebens von Mann und Frau in tragisch selbst verschuldeten Tat-Folgen bestehen, die aber den Menschen erst vom Naturwesen zum Kulturwesen machen; dass nach Gen 1 alles Kosmische und Irdische, was die Lebenswelt des Menschen und aller Lebewesen ausmacht, von Gott geschaffen ist, ja unvergleichlich erschaffen ist (hebr. Verb $b r^{\prime}$ ) - und darüber hinaus, dass dies alles „sehr gut" (Gen 1,31) geschaffen ist. All das wird konfessorisch, bekenntnishaft als wahr und wirklich erzäblend dargestellt. Mit anderen Worten, wenn Gen 1 auf die Feststellung Gottes zielt, dass das Geschaffene „sehr gut“ ist, dann soll hier nicht in einer fiktionalen Textwelt ein Urteil abgegeben werden; vielmehr wird nichts weniger behauptet, als dass die gegenwärtig real existierende Welt von ihrem Ursprung von Gott her wirklich gut erschaffen ist. Im konfessorisch erzäblenden Sprechakt wird ein faktualer Geltungsanspruch formuliert. Entsprechendes gilt in Gen 2 und 3 für die Grundbeziehungen und Grundbefindlichkeiten des Menschen.

Wir sollten daher von zwei sich ergänzenden erzählerischen Dimensionen in den Schöpfungserzählungen reden: In der Dimension, die ich die erzählerische Oberflächendimension nennen möchte, wird fiktional ein Handlungsablauf des göttlichen Erschaffens erzählt und insofern eine fiktionale Textwelt entworfen. Diese Dimension des fiktionalen Plots des schöpferischen Handelns, der ein ,Wie' des Erschaffens vorstellbar macht, ist jedoch nur Mittel zum entscheidenden Zweck: nämlich im konfessorisch erzäblenden Sprechakt mit faktualem Geltungsanspruch das ,Dass', die Tatsächlichkeit des Geschaffenseins von Welt und Mensch durch Gott, zu behaupten und darüber hinaus die Welt als von ihrem Ursprung in Gott her als gut geschaffen darzustellen. Dieser konfessorisch-faktuale Erzäblmodus als authentisches Erzäblen des textlich impliziten Erzählers, wie auch der vorausgesetzten Autoren, erscheint als die entscheidend intendierte Tiefendimension des Erzählten.

Im Hinblick auf die erzählerischen Paradoxien im biblischen Weltentwurf von Gen 1-3 (der gottbildliche Mensch und die sehr gute Schöpfung - der Mensch, der wie Gott sein will [Gen 3,5] und die Macht des Bösen) spricht Albrecht Ko-

29 Auch die später eingesetzte sog. Paradiesgeographie in Gen 2,10-14 lässt eine genaue Lokalisierung von Eden (hier Landschaft!) offen. 
schorke treffend von der „Koexistenz konfligierender Normenpaare“ (2012: 37176); gerade sie lösen eine kulturelle Dynamik und eine „nicht versiegende phantasmatische Energie“ (373) aus.

\section{Vom faktualen zum fiktionalen Erzäblen in alttestamentlicher Geschichtsscbreibung}

Die historisch-kritische Exegese hat seit dem 19. Jahrhundert zweifellos wertvolle Erkenntnisse zu Eigenart und Grundzügen alttestamentlicher Geschichtsschreibung und auch zu plausiblem Faktenwissen im Einzelnen zusammengetragen. Eher abwertend wurden dabei erkannte fiktive Elemente bzw. fiktionale Erzählzüge behandelt, was der Funktion dieser Elemente nicht gerecht wird. Darauf hat besonders Manfred Oeming aufmerksam gemacht (1984: 254-56). In meinem ganz ausschnitthaften Überblick hier versuche ich zu zeigen, dass man in der Bibel einen Trend von älteren eher faktualen zu jüngeren eber fiktionalen Geschichtsdarstellungen feststellen kann. Ich beziehe mich hier nicht auf die fundierenden und identitätsstiftenden Erzählungen von den Erzvätern bzw. Erzeltern Israels, vom Exodus aus Ägypten und dem Sinai-Ereignis mit ihren vielfach fiktionalen Inhalten und Erzählweisen bei gleichwohl begründeten faktualen Geltungsansprüchen. ${ }^{30}$ Mit Hans-Joachim Gehrke kann man diese Erzählungen als eine „intentionale Geschichte“ von Israels Anfängen im Sinne einer „Geschichte im Selbstverständnis“ (2005: 30) bezeichnen. ${ }^{31}$ - Auf faktuales Erzählen, gewiss auch mit fiktionalisierenden Erzählzügen und wohl auch z. T. mit fiktiven Inhalten bzw. Motiven treffen wir indes in alten und mehrfach bearbeiteten Geschichtsdarstellungen aus der (vorexilischen) Zeit der Königreiche Israel und Juda. Es versteht sich, dass solche Geschichtsschreibung Vergangenes deutend re-präsentiert. ${ }^{32}$

30 Vgl. z. B. zu den fiktionalen Zügen der Exodus-Erzählungen nur das Thema-Heft Exodus. Bibel und Kirche 62.4 (2007), bes. die Beiträge von K. Bieberstein (210-14) und H. Utzschneider (215-20).

31 Eingeführt wurde der Begriff der „intentionalen Geschichte“ von Gehrke (1994: 239-64, bes. $247 \mathrm{ff}$.): Erzählungen und Sagen ,als ,geglaubte“ Geschichte“, als das, „was in einer Gruppe von der Vergangenheit gezenßt, wie über sie geurteilt, was mit ihr gemeint ist ${ }^{6}$ - unabhängig davon, was die historische Forschung im modernen Sinne davon hält“ (247).

Ihr Wirklichkeitsbegriff ist nicht der von ,bruta facta'. Zur „Repräsentanzfunktion der Geschichtserzählung“, vgl. Kutzer (2006: 155), im Anschluss an P. Ricoeur und K. Wenzel. Vgl. forschungsgeschichtlich zu den alttestamentlichen Geschichtswerken Witte (2005). Einen konzentrierten Überblick bieten die Artikel „Geschichte“ und „Geschichtsschreibung“ von Cancik (1991a,b). 
5.1 Zur Geschichtsdarstellung aus der Zeit der vorexilischen Königreiche Israel und Juda (10. bis Anfang 6. Jh. v. Chr.)

\section{Höfische Historiographie in den Samuel- und Königsbüchern}

Faktual erzählt werden Elemente höfischer Historiographie in den Samuel- und Königsbüchern. Da wird hingewiesen auf Originaldokumente wie königliche Annalen. ${ }^{33}$ Aus solchen Annalen stammt die so typische synchronistische Datierung des Regierungsantritts eines Königs von Israel oder von Juda. ${ }^{34}$ Ebenso stammen aus höfischer Historiographie verlässliche faktual erzählte Angaben z. B. über hohe Beamte für König David in 2 Sam 8,15-18 und 20,23-26, für Salomo in 1 Kön 4,2-6. Solche Verzeichnisse geben wichtige Einblicke in die Innenpolitik der Könige. Historisch verlässlich sind ebenso Ortsangaben sowie weithin auch die räumlich-zeitliche Verortung faktual berichteter Ereignisse in der höfischen Geschichtsschreibung.

Geschichtsdarstellung, Geschichtsschreibung, verfährt perspektivisch und auch konstruktivistisch. Sie beleuchtet vergangenes Geschehen aus bestimmten interessegeleiteten Blickwinkeln. Sie wählt aus, sie vereinfacht selektiv und ordnet die Ereignisse nicht notwendig nach chronologischen Folgen, sondern planmäßig nach sachlichen Bezügen. An der sog. Hof- und Thronfolgegeschichte Davids, kann dies exemplarisch in Grundzügen deutlich werden. ${ }^{35}$

\section{Hof-und Thronfolgegeschichte Davids 2 Sam *9-20 + 1 Kön *1-2}

Eine keineswegs nur ,volkstümliche', sondern in Teilen meisterhafte Erzählkunst zeigt sich in dem literarischen Komplex, der üblicherweise als $H o f$ - und Thronfolgegeschichte Davids in 2 Sam *9-20+1Kön *1-2 bezeichnet wird. Die überaus umfangreiche, kontroverse und verschlungene Forschungsgeschichte des komplexen, sicher erweiterten und (mehrfach) bearbeiteten Werkes haben Walter Dietrich und Thomas Naumann vorbildlich dargestellt

33 So etwa auf ein Buch der Begebenheiten/Chronik Salomos 1 Kön 11,41; Chronik der Könige Israels 1 Kön 14,9; Chronik der Könige Judas 1 Kön 15,7. Vgl. u. a. auch den primären Bericht über die Kultreform und Kultzentralisation des judäischen Königs Joschija 622 v. Chr. in 2 Kön *23,4-15.

34 Ein Beispiel solcher synchronistischen Geschichtsschreibung, die Regierungsdaten der Könige des Nordreichs Israel zu denen von Königen des Südreichs Juda in Beziehung setzt, ist etwa 2 Kön 18,1: „Im dritten Jahr des Hoschea, des Sohnes Elas, des Königs von Israel, wurde Hiskija, der Sohn des Ahas, König von Juda“.

35 Ähnliches wäre an der sog. Geschichte vom Aufstieg Davids zum Königtum in 1 Sam *16,14-2 Sam 5,12 zu zeigen. Im sog. „Deuteronomistischen Geschichtswerk“ (Dtn + Jos, Ri, Sam, Kön), das in seiner Endgestalt erst dem späteren 6. Jh. v. Chr. angehört, wird, basierend auf durchaus verlässlichen Quellen, mit übergreifenden Geschichtskonstruktionen und Leitideen vom Deuteronomium her textlich eine fiktionale Geschichtswelt Israels entworfen und erzählt. 
(1995: 167-295). Ein Grundstock dieses Werkes darf auch heute noch zu den ältesten schriftlichen Überlieferungen des Alten Testaments gerechnet werden. ${ }^{36}$ Dass der Grundstock des Werks aus dem Kreis des Jerusalemer königlichen Hofes stammt und auf Grund der berichteten Einzelbegebenheiten eine relativ zeitnahe Beziehung zur Regierungszeit Salomos haben muss, ist mit Martin Noth (1968: 11-13) u. a. noch immer eine plausible Annahme. ${ }^{37}$ Die höfische Perspektive verbindet die Teile des Werks, dessen Kernkomposition die Kapitel 2 Sam 15-20 bilden. Sie handeln vom Aufstand des Abschalom gegen seinen Vater David und von der Niederschlagung von Rebellionen gegen David. Wie kunstvoll hier erzählt und konstruiert wird, zeigt sich schon in der chiastischen Abfolge von Begegnungsszenen, die einander korrespondieren. ${ }^{38}$ Das erweiterte Zentrum des literarischen Komplexes in 2 Sam 13-20 verrät eine prodynastische Perspektive und eine davidfreundliche Tendenz, während die rahmenden Kapitel 2 Sam *11-12 und 1 Kön *1-2 davidkritische bzw. salomokritische Tendenzen aufweisen (vgl. Dietrich/Naumann 1995: 194 f.).

Dass in der Hof- und Thronfolgegeschichte Davids dominant und grundlegend faktual erzählt wird, mit dem Anspruch authentisch reale Sachverhalte darzustellen, ist kaum zu bestreiten. Dafür sprechen nicht nur die begrenzte höfische Perspektive, die plausible situative Einordnung von Einzelbegebenheiten und ihr relativ enger zeitlicher Bezugsrahmen, sondern auch, dass Themen rückblickender David- und vor allem Salomo-Rezeption noch keine Rolle spielen. So wird David nicht etwa als frommer Liederdichter vorgestellt, sondern durchaus als Machtmensch mit menschlichen Schwächen und Gefährdungen; durch Salomo wird noch nichts von seiner später sprichwörtlichen Weisheit, seinem Reichtum, seiner Herrlichkeit ausgemalt.

Mit dem faktualen Erzäblen verbinden sich allerdings fiktionalisierende Erzäblverfahren: Dazu gehören facetten- und farbenreiche Schilderungen von Charakteren und menschlichen Konflikten, die implizite Figur eines auktorialen allwissenden Erzählers, Gespräche mit wörtlicher Wiedergabe des gewiss nicht protokollierten

36 Vgl. G. Hentschel (2012: 297). Für ihn bleibt allerdings weiterhin offen, wie zeitnah die Erzählung zu den erzählten Ereignissen entstanden ist.

37 Ähnlich betont z. B. F. Crüsemann jedenfalls das höfische Blickfeld des Erzählers, der auch sein Publikum primär am Hof gehabt haben muss (1978: 185-87). Zur Diskussion der Datierungsfragen der Thronfolgegeschichte vgl. resümierend Seiler (1998: 314-26) mit Argumenten für eine Datierung der Grundschicht noch in die Zeit Salomos (319-21). E. Blum bezeichnet die von ihm so genannte „Hofgeschichte Davids“ zwar als "traditionale Erzählung“, deren Autor „die Problematik selbstbestimmter Weltbemächtigung“ zu seinem Gegenstand macht (2000: 29-37), versteht aber, wenn ich recht sehe, den „Erzähler“ doch relativ zeitnah zu den erzählten Ereignissen. W. Dietrich (2000: 41-44, 45-47) erkennt in 2 Sam *11-12 und 1 Kön *1-2 eine „Grunderzählung“, deren zeitlicher Horizont ereignisnah nicht über die Zeit Salomos hinausgreift und streng auf Jerusalem bezogen ist (46). Zu z. T. viel späteren Datierungen, die freilich mit unterschiedlichen literar- und redaktionskritischen Ansätzen zusammenhängen, vgl. z. B. O. Kaiser (2000) und J. van Seters (2000) sowie die Einleitung von de Pury/Römer (2000: 2).

38 Vgl. dazu die Nachweise bei Dietrich/Naumann (1995: 271; bes. nach J. P. Fokkelman). 
Gesagten. All das dient einer wirkungsbezogenen und aktualisierenden Darstellung, die den Hörer bzw. Leser in ihren Bann zieht und ihm Paradigmen menschlichen Verhaltens emotional ansprechend vor Augen stellt, die auch zur Anfrage an den Rezipienten werden können. $\mathrm{Zu}$ beobachten ist auch eine charakteristische Ambiguität und Zweideutigkeit des Erzählens: Gott lenkt die Geschichte, was den Akteuren verborgen bleibt, und zugleich wird deren Verhalten von innen her in begrenzter Selbstbestimmung gesteuert (Rüterswörden 2009: 347, 358). Solche Ambiguität als fiktionaler Zug im Erzählen dient einer theologischen Absicht; sie will die verborgene, im äußeren Geschehen verwechselbare und doch wirksame Gegenwart Gottes aufdecken, die kein bloßer Bericht erfassen kann. Auch fiktive Inhalte bzw. Motive kommen vor. So dürfte das in der Erzähltradition bekannte, dem Verfasser vorgegebene Motiv vom ,Todesbrief ${ }^{39}$ in 2 Sam 11 aufgenommen worden sein; es begegnet in dem Schreiben des David an seinen Feldherrn Joab, das das erklärte Ziel hat, Urija, den Mann der von David begehrten Batscheba, dem Tod in der Schlacht zu überantworten. Der Erzähler weiß auch noch den Inhalt des ja streng geheimen Briefes im Wortlaut zu zitieren. Es ist kaum von der Hand zu weisen, dass der Erzähler hier ein fiktionales Element einsetzt, ein bekanntes Motiv benutzt, um David als arglistig handelnden König erscheinen zu lassen. Doch all dies ändert nichts daran, dass dominant zumindest im Grundstock des Werks und in den relativ zeitnah erzählten Einzelepisoden faktual erzählt wird.

\subsection{Zur Geschichtsdarstellung in den Chronikbüchern (1 und 2 Chronik) mit Blick auf die Erzählerzeit}

Von $1 \mathrm{Chr} 11$ bis zum Ende in $2 \mathrm{Chr} 36$ bieten die beiden Chronikbücher aus dem späten 4. oder schon aus dem 3. Jh. v. Chr. die Geschichte allein der von David abstammenden Könige Judas. Sie setzt ein mit dem hochgerühmten David als Kultstifter, Tempelbaubegründer und Psalmdichter, sodann (ab $2 \mathrm{Chr}$ 1) mit Salomo. Als Hauptvorlage dient den Verfassern eine hebräische Textfassung der Bücher Samuel und Könige. ${ }^{40}$ Ihre Geschichtsdarstellung ist religiös belehrende Schriftauslegung. Mit ihrer schriftgelehrten geschichtstheologischen Unterweisung haben die Chronikbücher zweifellos insgesamt einen weitgehend fiktionalen Erzäblcharakter. So aber schaffen sie einen Raum für religiöse Belehrung über Gottes Wirken in der Geschichte und verdeutlichen an eindrücklichen Paradigmen das rechte Tora-gemäße Leben Israels. Charakteristisch ist ihre Lehre von einer innerweltlichen göttlichen Vergeltung, die jedoch nicht absolut ist und die Möglichkeit der Vergebung einschließt, ebenso charakteristisch ist ihre Beto-

39 Hinweise zur Herkunft, Verbreitung und ferner zur Funktion des literarischen Motivs vom ,Todesbrief' vgl. bei Dietrich/Naumann (1995: 243 f.).

40 Diese hebräische Fassung weicht von der überlieferten masoretischen Textfassung leicht ab, vgl. G. Steins (2012: 322). 
nung des geistigen Zentrums Israels in der Tora als Kult- und Lebensordnung und der Tora-Frömmigkeit sowie des sichtbaren Zentrums im Tempel zu Jerusalem. Eigentümlich für die Chronikbücher ist auch die Vorstellung, dass die Davididen, die Könige in Jerusalem, nur irdische Platzhalter der wahren und eigentlichen Königsherrschaft JHWHs sind, eine kreative Neuinterpretation der alten Verheißung (2 Sam 7*) ewig dauernden Bestands des davidischen Königtums. Das Bild der davidischen Zeit, das die Chronik entwirft, ist in mancherlei Hinsicht historische Fiktion. So wird vieles aus der gegenwärtigen Tempelordnung der Erzählerzeit ${ }^{41}$ in die ideale davidische erzählte Zeit zurückverlegt. Die Chronikbücher haben kaum eigenständigen historischen Wert für die erzäblte ältere Zeit Judas. ${ }^{42}$ Wohl aber haben sie einigen nicht zu unterschätzenden historischen Wert für die Erzäblerzeit, in der die Bücher entstanden sind. ${ }^{43}$

Aus heutiger Sicht können wir daher sagen: Die Chronikbücher erzählen weitgehend fiktional in Bezug auf ibre erzäblte Zeit, die Königszeit Judas von David bis zum babylonischen Exil. Am Ende steht das sog. Edikt des Perserkönigs Kyros, mit dem die Zeit der Restauration Israels nach dem Exil beginnt. Mit diesem Edikt fordern die Chronikbücher zum Aufbruch und zur Rückkehr aus Exil und weltweiter Diaspora des Judentums nach Jerusalem auf und sind so auf ihre zeitgenössischen wie auf zukünftige Leser und Leserinnen hin orientiert. Die Bücher erzählen im Blick auf ibre Entstehungszeit, die Erzäblerzeit, indirekt historisch-faktual, da sie historische Gegebenheiten der Erzählerzeit bezeugen bzw. gut begründet darauf schließen lassen. Mit ihrer weitgehend fiktional erzählenden Darstellung der Königszeit Judas verbinden die Chronikbücher aber religiöse Unterweisung für die zeitgenössischen Adressaten und für spätere Rezipienten und deren Lebenswirklichkeit. Die Chronikbücher zielen letzten Endes auf die Tora-gemäße Bewährung des Lebens Israels in der Gegenwart. Daher erzählen sie implizit immer auch normativ-faktual.

\section{Schlussbemerkungen}

Aufs Ganze gesehen scheint mir für biblische Erzähltexte charakteristisch, dass im Modus ihrer Darstellung eine Doppelbödigkeit und eine Art hierarchisierte, in der Rangordnung unterschiedlich gewichtete Mehrfachbestimmung wirksam

41 So z. B. die Einteilung der levitischen Musiker in Klassen und insgesamt die Dienstklassen der Priester und der Leviten.

42 Außer den Büchern Gen bis 2 Kön und Genealogien werden noch besondere Nachrichten in 2 Chr 11,5-10; 20,1-4; 26,6-14 und 32,30 genannt, vgl. Kaiser (1992: 146). Doch ist der Quellenwert der Hinweise auf unbekannte außerbiblische Quellen sehr umstritten, vgl. G. Steins (2012: 322).

43 Das gilt nicht nur für die den Erzählern zeitgenössischen Tempelordnungen und Dienstklassen von Priestern und Leviten, sondern auch für historische Ereignishintergründe der chronistischen Darstellung. So hat Peter Welten plausibel dafür argumentiert, dass die Kriegserzählungen (2 Chr 13; 14; 20) die beginnenden Auseinandersetzungen zwischen Ptolemäern und Seleukiden im 3. Jh. v. Chr. und die damit gegebene Gefährdung der frühjüdischen Gemeinde in Jerusalem reflektieren (1973: 115-75). 
ist. Sie hängt wesentlich mit dem eingangs erwähnten konfessorischen Charakter und mit der paradigmatischen Transparenz der Texte auf neue Lebensgeschichten und Erfahrungen von Menschen zusammen, die auf neue Aneignung zielt. So zeigt sich eine implizite Dimension des normativ-faktualen Erzählens etwa in Evangelienerzählungen mit authentischem, dokumentarisch-faktualem Geltungsanspruch, genauso aber in unzweideutig fiktional erzählten Texten wie im Ijobbuch. Auf die Doppelbödigkeit von fiktionalem Plot der Schöpfungsakte und Urzeitgeschehnisse und einem intendierten konfessorisch faktualen Geltungsanspruch von der Wirklichkeit der Schöpfung Gottes stießen wir in den Schöpfungserzählungen.

In biblischen Geschichtsdarstellungen kann ebenfalls durchaus auf Produktions- wie Überlieferungs- und Rezeptionsebene ein faktualer Geltungsanspruch erkannt werden. Fiktionale Elemente und Erzählweisen (dominant besonders in der Endgestalt des Deuteronomistischen Geschichtswerks, in 1-2 Chr wie in 2 Makk) haben jedoch wichtige Funktionen. ${ }^{44}$ Sie können die verborgene wirksame Gegenwart Gottes im Geschehen aufdecken, ohne menschliche Freiheit auszuschalten, sie können ebenso Geschehen idealtypisch verdichten zum ParadigmatischTypischen, das auf Belehrung über das, was sein sollte, also auf Applikation, zielt.

\section{Literatur}

Aristoteles (2010) Poetik. Griechisch/Deutsch. Übers. u. hg. Manfred Fuhrmann. Reclams Universal-Bibliothek. Stuttgart: Reclam.

Backhaus, Knut (2007) „Lukas der Maler: Die Apostelgeschichte als intentionale Geschichte der christlichen Erstepoche“. Historiographie und fiktionales Erzäblen: Zur Konstruktivität in Geschichtstheorie und Exegese. Biblisch-theologische Studien 86. Hgg. Knut Backhaus und Gerd Häfner. Neukirchen-Vluyn: Neukirchener. 30-66.

Bar-Efrat, Shimon (2006) Wie die Bibel erzäblt: Alttestamentliche Texte als literarische Kunstwerke verstehen. Übers. Kerstin Menzel. Bearb. v. Thomas Naumann. Gütersloh: Gütersloher Verlagshaus.

44 Oeming hat in neun Punkten Funktionen von sog. „Fiktionen“ in der alttestamentlichen Geschichtsschreibung zusammengestellt (1984: 262-65). Immer geht es darum, „eine Wahrheit am Gewesenen“ aufzudecken, „die in der bloßen Beschreibung nicht aufgeht“ (262). Im Einzelnen nennt er folgende Funktionen des Fiktiven, die ich hier in verdichteter Form wiedergebe: 1. die verborgene Gegenwart und Wirksamkeit Gottes aufdecken; 2. kerygmatisch-konfessorisch (glaubensbekennend und -verkündigend) wirken; 3. einen Ort für theologische Konzeptionen, für das Durchdenken von Gott-, Welt- und Menschenverständnis schaffen; 4. ermöglichen zu erzählen, wie es hätte sein sollen (normativ-programmatisch); 5. das Geschehen auf das Wesentliche „idealtypisch“ bzw. paradigmatisch verdichten; 6. das Geschehene interpretierend aktualisieren, für die jeweilige Jetztzeit applikativ bedeutsam machen; 7. für die Zeit des Erzählers (nicht für die erzählte Zeit) historisches Wissen mitteilen; 8. einem ätiologischen (begründenden und legitimierenden) Interesse dienen; 9. Verbindungen zwischen ursprünglich getrennten Traditionen herstellen. 
Barsch, Achim (2001) „Literarizität“. Metzler Lexikon Literatur- und Kulturtheorie: Ansätze - Personen - Grundbegriffe. Hg. Ansgar Nünning. 2. Aufl. Stuttgart Weimar: J. B. Metzler. 376-77.

Ben-Chorin, Schalom (1991) „Die Bedeutung der Bibel für die Kultur Europas und der Welt“". Die Freude an Gott - unsere Kraft. FS Otto Bernhard Knoch. Hg. Johannes Joachim Degenhardt. Stuttgart: Katholisches Bibelwerk. 299-307.

Bieberstein, Klaus (2007) „Geschichte und Geschichten vom Auszug aus Ägypten - fiktional und wahr zugleich“. Exodus. Sonderheft Bibel und Kirche 62.4: 21014.

Blum, Erhard (2000) „Ein Anfang der Geschichtsschreibung?“. Die sogenannte Thronfolgegeschichte Davids: Neue Einsichten und Anfragen. Orbis Biblicus et Orientalis 176. Hgg. Albert de Pury und Thomas Römer. Göttingen: Vandenhoeck \& Ruprecht. 4-37.

Bodine, Walter R. (1995) Discourse Analysis of Biblical Literature: What It Is and What It Offers. The Society of Biblical Literature Semeia Studies 27. Hg. Walter R. Bodine. Atlanta: Scholars Press.

Bovon, François (1989) Das Evangelium nach Lukas: 1. Teilbd. (Lk 1,1-9,50). Evangelisch-Katholischer Kommentar zum Neuen Testament. Zürich: Benzinger / Neukirchen-Vluyn: Neukirchener.

Burridge, Richard A. (1992) What are the Gospels?: A Comparison with GraecoRoman Biography. Society for New Testament Studies. Monograph Series 70. Cambridge: Cambridge Univ. Press.

Cancik, Hubert (1991a) „Geschichte“. Neues Bibel-Lexikon I. Hg. Manfred Görg. Zürich: Benziger. 809-13.

Cancik, Hubert (1991b) „Geschichtsschreibung“. Neues Bibel-Lexikon I. Hg. Manfred Görg. Zürich: Benziger. 813-22.

Crüsemann, Frank (1978) Der Widerstand gegen das Königtum: Die antiköniglichen Texte des Alten Testaments und der Kampf um den früben israelitischen Staat. Wissenschaftliche Monographien zum Alten und Neuen Testament 49. NeukirchenVluyn: Neukirchener.

Die Bibel. Einheitsübersetzung der Heiligen Schrift. Gesamtausgabe. Psalmen und Neues Testament Ökumenischer Text (2003) 4. Aufl. Stuttgart: Verlag Katholisches Bibelwerk.

Dietrich, Walter (2000) „Das Ende der Thronfolgegeschichte“. Die sogenannte Thronfolgegeschichte Davids: Neue Einsichten und Anfragen. Orbis Biblicus et Orientalis 176. Hgg. Albert de Pury und Thomas Römer. Göttingen: Vandenhoeck \& Ruprecht. 38-69.

Dietrich, Walter, und Thomas Naumann (1995) Die Samuelbücher. Erträge der Forschung 287. Darmstadt: Wissenschaftliche Buchgesellschaft.

Eco, Umberto (2012) Das offene Kunstwerk [1977]. Übers. Günter Memmert. 12. Aufl. Suhrkamp-Taschenbuch Wissenschaft. Frankfurt a. M.: Suhrkamp. 
Fludernik, Monika (1996) Towards a ,Natural ${ }^{\star}$ Narratology. London/New York: Routledge.

- (2001) „Fiction vs. Non-Fiction: Narratological Differentiations“. Erzäblen und Erzäbltheorie im 20. Jabrbundert. FS Wilhelm Füger. Hg. Jörg Helbig. Heidelberg: C. Winter. 85-103.

- (2010) Erzäbltheorie: Eine Einführung [2006]. 3. Aufl. Darmstadt: Wissenschaftliche Buchgesellschaft.

Fohrer, Georg (1989) Das Buch Hiob [1963]. Kommentar zum Alten Testament XVI. Gütersloh: Gütersloher Verlagshaus.

Fokkelman, Jan P. (1981-93) Narrative Art and Poetry in the Books of Samuel. A Full Interpretation Based on Stylistic and Structural Analyses. Bd. I-IV. Studia Semitica Neerlandica 20.23.27.31. Assen: Van Gorcum.

Fuchs, Gisela (1993) Mythos und Hiobdichtung: Aufnabme und Umdeutung altorientalischer Vorstellungen. Stuttgart: Kohlhammer.

Fricke, Klaus Dietrich, Benedikt Schwank und Joachim Lange (1981) Hgg. Ökumenisches Verzeichnis der biblischen Eigennamen nach den Loccumer Richtlinien [1971]. 2. Aufl. Stuttgart: Deutsche Bibelgesellschaft.

Gehrke, Hans-Joachim (1994) „Mythos, Geschichte, Politik - antik und modern“. Saeculum 45: 239-64.

- (2005) „Die Bedeutung der (antiken) Historiographie für die Entwicklung des Geschichtsbewußtseins". Die antike Historiographie und die Anfänge der christlichen Geschichtsschreibung. Beihefte zur Zeitschrift für die neutestamentliche Wissenschaft und die Kunde der älteren Kirche 129. Hg. Eve-Marie Becker. Berlin/New York: de Gruyter. 29-51.

Genette, Gérard (1992) Fiktion und Diktion. Übers. Heinz Jatho. München: W. Fink.

Goldschmidt, Lazarus (2002) Übers. Der babylonische Talmud. Bd. II. Berlin: Jüdischer Verlag im Suhrkamp-Verlag.

HAH: Gesenius, Wilhelm, Rudolf Meyer und Herbert Donner (2013) Hgg. Hebräisches und aramäisches Handwörterbuch über das Alte Testament. 1987-2012. 18. Aufl. Berlin/Heidelberg/New York: Springer.

Hentschel, Georg (2012) „Die Samuelbücher“. Einleitung in das Alte Testament. 8. Aufl. Hgg. Christian Frevel und Erich Zenger. Stuttgart: Kohlhammer. 290-300.

Irsigler, Hubert (2007) „Hosea 11 und das Problem der Rückfrage nach der originären Gestalt von Prophetie“. Literatur- und sprachwissenschaftliche Beiträge zu alttestamentlichen Texten. Symposion in Hólar i Hjaltadal, 16.-19. Mai 2005. FS Wolfgang Richter. Arbeiten zu Text und Sprache im Alten Testament 83. Hgg. Sigurđur Örn Steingrímsson und Kristinn Ólason. St. Ottilien: Eos Verlag. 87121.

Kaiser, Otto (1992) Grundriß der Einleitung in die kanonischen und deuterokanonischen Scbriften des Alten Testaments. Bd. 1. Gütersloh: Gütersloher Verlagshaus. 
- (2000) „Das Verhältnis der Erzählung vom König David zum sogenannten Deuteronomischen Geschichtswerk: Am Beispiel von 1 Kön 1-2 untersucht. Ein Gespräch mit John Van Seters“. Die sogenannte Thronfolgegeschichte Davids: Neue Einsichten und Anfragen. Orbis Biblicus et Orientalis 176. Hgg. Albert de Pury und Thomas Römer. Göttingen: Vandenhoeck \& Ruprecht. 94-112.

Klein, Christian, und Matías Martínez (2009) „Wirklichkeitserzählungen: Felder, Formen und Funktionen nicht-literarischen Erzählens“. Wirklichkeitserzäblungen: Felder, Formen und Funktionen nicht-literarischen Erzäblens. Stuttgart: Metzler. 1-13. Koschorke, Albrecht (2012) Wabrheit und Erfindung: Grundzüge einer Allgemeinen Erzäbltheorie. Frankfurt a. M.: Fischer.

Kutzer, Mirja (2006) In Wabrheit erfunden: Dichtung als Ort theologischer Erkenntnis. Ratio fidei 30. Regensburg: Pustet.

Licht, Jacob (1986) Storytelling in the Bible. Jerusalem: The Magnes Press.

Liss, Hanna (2004) „Kanon und Fiktion: Zur literarischen Funktion biblischer Rechtstexte“. Biblische Notizen 121: 7-38.

Martínez, Matías, und Michael Scheffel (2012) Einfübrung in die Erzäbltheorie. 9. Aufl. München: C.H. Beck.

Mauz, Andreas (2009) „In Gottesgeschichten verstrickt: Erzählen im christlichreligiösen Diskurs“. Wirklichkeitserzäblungen: Felder, Formen und Funktionen nichtliterarischen Erzäblens. Hgg. Christian Klein und Matías Martínez. Stuttgart: Metzler. 192-216.

Metz, Johann Baptist (1973) „Kleine Apologie des Erzählens“. Concilium 9: 334-41.

Noth, Martin (1968) Könige: 1. Teilbd. [1-16]. Biblischer Kommentar - Altes Testament IX/1. Neukirchen-Vluyn: Neukirchener.

Oeming, Manfred (1984) „Bedeutung und Funktionen von ,Fiktionen' in der alttestamentlichen Geschichtsschreibung". Evangelische Theologie 44: 254-66.

Pesch, Rudolph (1986) Die Apostelgeschichte: 1. Teilbd. (Apg 1-12). EvangelischKatholischer Kommentar zum Neuen Testament. Zürich: Benzinger / Neukirchen-Vluyn: Neukirchener.

Pury, Albert de, und Thomas Römer (2000) „Einleitung“. Die sogenannte Thronfolgegeschichte Davids: Neue Einsichten und Anfragen. Orbis Biblicus et Orientalis 176. Hgg. Albert de Pury und Thomas Römer. Göttingen: Vandenhoeck \& Ruprecht. 1-3.

Rüterswörden, Udo (2009) „Erwägungen zur Anthropologie der Thronfolgegeschichte". Anthropologische Aufbrüche: Alttestamentliche und interdisziplinäre Zugänge zur historischen Anthropologie. Forschungen zur Religion und Literatur des Alten und Neuen Testaments 232. Hg. Andreas Wagner. Göttingen: Vandenhoeck \& Ruprecht. 345-58.

Schmitz, Barbara (2006) „Die Bedeutung von Fiktionalität und Narratologie für die Schriftauslegung". „Der Leser begreife!": Vom Umgang mit der Fiktionalität biblischer Texte. Hg. Heinz-Günther Schöttler. Münster: LIT. 137-49. 
Schöttler, Heinz-Günther (2006) Hg. „Der Leser begreife!": Vom Umgang mit der Fiktionalität biblischer Texte. Unter Mitarbeit von Birgitt Brink u.a. Biblische Perspektiven für Verkündigung und Unterricht 1. Münster: LIT.

Seiler, Stefan (1998) Die Geschichte von der Thronfolge Davids (2 Sam 9-20; 1 Kön 12). Beihefte zur Zeitschrift für die alttestamentliche Wissenschaft 267. Berlin/New York: W. de Gruyter.

Seip, Jörg (2002) „Die Wahrheit erfinden? Eine Skizze zum fruchtbaren Spannungsverhältnis von Offenbarung und Fiktionalität". Zeitschrift für Katholische Theologie 124: 190-200.

Steins, Georg (2012) „Die Bücher der Chronik“. Einleitung in das Alte Testament. 8. Aufl. Hgg. Christian Frevel und Erich Zenger. Stuttgart: Kohlhammer. 313-31.

Sternberg, Meir (1987) The Poetics of Biblical Narrative: Ideological Literature and the Drama of Reading. Bloomington: Indiana Univ. Press.

Van Seters, John (2000) „The Court History and DTRH: Conflicting Perspectives on the House of David“. Die sogenannte Thronfolgegeschichte Davids: Neue Einsichten und Anfragen. Orbis Biblicus et Orientalis 176. Hgg. Albert de Pury und Thomas Römer. Göttingen: Vandenhoeck \& Ruprecht. 70-93.

Utzschneider, Helmut (2007) „Gottes langer Atem: Erzählung, Fakt und Fiktion in Ex 1-14 (15)“. Exodus. Sonderheft Bibel und Kirche 62.4: 215-20.

Weinrich, Harald (1973) „Narrative Theologie“. Concilium 9: 329-33.

Welten, Peter (1973) Geschichte und Geschichtsdarstellung in den Chronikbüchern. Wissenschaftliche Monographien zum Alten und Neuen Testament 42. Neukirchen-Vluyn: Neukirchener Verlag.

Wenzel, Knut (1996) „Zu einer theologischen Hermeneutik der Narration“. Theologie und Philosophie 71: 161-86.

- (1997) Zur Narrativität des Theologischen: Prolegomena zu einer narrativen Texttheorie in soteriologischer Hinsicht. Regensburger Studien zur Theologie 52. Frankfurt a. M.: Lang.

- (2008) Glaube in Vermittlung: Theologische Hermeneutik nach Paul Ricoeur. Freiburg i.Br.: Herder.

Witte, Markus (2005) „Von den Anfängen der Geschichtswerke im Alten Testament - Eine forschungsgeschichtliche Diskussion neuerer Gesamtentwürfe". Die antike Historiographie und die Anfänge der christlichen Geschichtsschreibung. Beihefte zur Zeitschrift für die neutestamentliche Wissenschaft und die Kunde der älteren Kirche 129. Hg. Eve-Marie Becker. Berlin New York: de Gruyter. 53-81.

Wolf, Werner (1993) Ästhetische Illusion und Illusionsdurchbrechung in der Erzäblkunst: Theorie und Geschichte mit Schwerpunkt auf englischem illusionsstörenden Erzäblen. Anglia 32. Tübingen: Niemeyer.

Zipfel, Frank (2001) Fiktion, Fiktivität, Fiktionalität: Analysen zur Fiktion in der Literatur und zum Fiktionsbegriff in der Literaturwissenschaft. Allgemeine Literaturwissenschaft - Wuppertaler Schriften 2. Berlin: Erich Schmidt. 